Fourth International Conference on Sustainable Construction Materials and Technologies http://www.claisse.info/Proceedings.htm

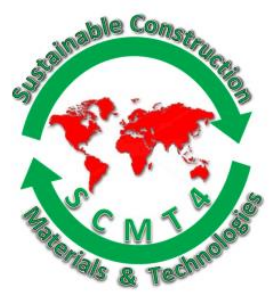

SCMT4

Las Vegas, USA, August 7-11, 2016

\title{
Bond Behavior Between External Composite Reinforcements and Masonry Substrates
}

\author{
Marianovella Leone ${ }^{1 \mathrm{a}}$, Margherita Stefania Sciolti ${ }^{1 \mathrm{~b}}$, Francesco Micelli ${ }^{1 \mathrm{c}}$ and Maria \\ Antonietta Aiello ${ }^{1 d}$ \\ ${ }^{1}$ Università of Salento, Department of Engineering for Innovation, Via per Monteroni, 73100, LECCE, \\ ITALY, ${ }^{1 a}$ Email: <marianovella.leone@unisalento.it>, ${ }^{l b}$ Email: <margherita.sciolti@unisalento.it>, \\ ${ }^{1 c}$ Email: <francesco.micelli@unisalento.it>, ${ }^{1 d}$ Email: $<$ antonietta.aiello@unisalento.it>.
}

\begin{abstract}
The need to guarantee higher safety levels of masonry structures under both short and long term conditions, have led to the use of new materials and technologies, in conjunction or in place of traditional ones. In this context fiber-reinforced composite materials have gained an increasing success, mostly for strengthening, retrofitting and repair existing structures. As well known, the bond performance between the reinforcement and the masonry substrate is a critical aspect as it influences the effectiveness of the technique. The bond depends on many parameters as mechanical proprieties of the substrate, interface and reinforcement, bond length, type of test, environmental conditions etc.

The research work of the authors was devoted to this topic from many years and several of the above parameters were analysed.

In the present paper the most recent experimental results are reported and discussed; they refer to the analysis of bond between masonry made by natural stones and reinforcement. At this scope a single face shear test has been carried out, varying the substrate configuration and the stiffeness of the FRP reinforcement. In particular a kind of calcerous stone, typically used in the Mediterranea area, was considered and syntetic and natural fibers were used as reinforcement. The effect of these analysed parameters was investigated in terms of bond strength, mode of failure and strains path along the bonded length. In addition a theoretical analysis was done based on the suggestions available in the Italian guideline. The obtained results show that both the stiffness of the reinforcement and the presence of the mortar joints influence the interface behavior; in particular the tests on masonry substrates furnish higher bond strength with respect to those made using stone unit subtrates, despite the poorer mechanical properties of masonry. In addition the analytical bond strengths evaluated according to the Italian Guideline furnish a good estimation of the excperimental data in the case of specimens realized with stone units.
\end{abstract}

\section{INTRODUCTION}

The use of externally bonded Fiber Reinforced Polymer (FRP) reinforcement for strengthening masonry structures is a promising technique successfully utilized in conjunction or in place of traditional technologies. At the date, the main applications are related to the repair of damages after earthquakes and to improve the seismic capacity of existing structures. 
Recently, the interest of the scientific community has been addressed to both deepen the knowledge when "traditional" FRP materials (carbon and glass fibers) are used and to move toward the use of new composites. In particular, FRP composites realized with basalt, hemp, flax and steel fibers and reinforcement obtained by embedding dry or pre-impregnated grids in an inorganic matrix (cement based mortar/lime based mortar) are gaining an increasing attention from researchers and industries .

In this context, the interface performance between the reinforcement and the masonry substrate is a crucial problem as it influences the effectiveness of the technique. In general, the adhesion between the existing and new materials involves the fibers, the matrix layer and the substrate; it depends on many parameters, as mechanical properties of the substrate, interface and reinforcement, bond length, type of test, environmental conditions etc. Specifically referring to the masonry the investigation and validation of results become more complex because of the wide variety of materials utilized in terms of both blocks and mortar. The research work of the authors was devoted to this topic from many years (Leone et. Al. 2014, Leone et al. 2015, Sciolti et. al. 2012, Sciolti et al. 2015) and several of the above parameters were analyzed, however further investigations are needed in this area in order to extend and validate the available design guidelines.

In the present paper, the bond between different types of FRP composite reinforcements and masonry elements was investigated by single face shear test. In particular, natural, synthetic and steel fibers were considered. Another important focused aspect was the influence of the substrate configuration; at this scope the substrate was made by only stone units or by stone units joined through a hydraulic mortar. This investigation is particularly interesting as in real applications the reinforcement is bonded to a composite substrate (stones plus mortar joints), however most of available experimental results are related to a substrate made only by stone units, considering that the presence of joints may slightly influence the bond performance. In (de Felice et al. 2015) the bond behavior referring to a substrate made by only brick units or masonry prisms (bricks and mortar joints) is investigated and discussed in order to validate or propose reliable modification of the available relationships (CNR DT 200/R1), that generally are deducted from experimental results related to brick/stone units. It was found that the specimens made by masonry substrate led to a slight increase of the global bond strength with respect to the brick unit substrate even if the experimental results related to masonry are more scattered. According to the authors such result may be related to both the anisotropy of the bricks and to the interlocking effect provided by the joints. A similar investigations has been planned and performed by authors referring to masonry made by natural stones, specifically a calcareous stone called "lecce stone". The obtained experimental data were analyzed and discussed in terms of bond strength, kind of failures and strain path along the bond length. Moreover, the analytical predictions of the bond strength suggested in the Italian Guideline (CNR DT 200/R1) were compared with the experimental results; this comparison allows making interesting suggestions concerning the reliability of the available relationships when referring to masonry prisms instead of stone units.

\section{EXPERIMENTAL CAMPAIGN}

The performed experimental campaign aims to study the interface behavior between FRP reinforcements and a masonry substrate realized with Lecce stone. At this scope single face shear test were carried out varying the stiffness of the reinforcement, the masonry configuration and the bond length. In the Table 1 the experimental program is reported; twenty-seven bond tests are presented and discussed. Five different types of fibers are analyzed: Carbon Fiber Reinforced Polymer (CFRP), Basalt Fiber Reinforced Polymer (BFRP), Steel Fiber Reinforced Polymer (SFRP), Flax Fiber Reinforced Polymer (FFRP) and Hemp Fiber Reinforced Polymer (HFRP). In all cases epoxy resin was used as matrix. Two different substrates were considered in the present experimental campaign: natural calcareous stone units, widely utilized in the south of Italy and called "Lecce Stone", and masonry prisms realized joining Lecce stone units with 10 $\mathrm{mm}$ thick joints of a hydraulic lime mortar provided by Tassullo SpA, Italy. The specimens are listed 
using the following label: the first notation indicates the type of substrate (BS= Blocks of Lecce Stone, $\mathrm{MS}=$ masonry prisms realized with blocks of Lecce stone and four mortar joints, MS2= masonry prisms realized with blocks of Lecce stone and one mortar joint); the second notation individuates the kind of reinforcement $(C=C F R P$ sheet; $B=B F R$ sheet; $S=S F R P$ sheet; $F=$ FFRP sheet; H=HFRP sheet); the third number refers to the test sequence of similar specimens; the last notation, if present, designs the bond test with bond length of $135 \mathrm{~mm}$.

Table 1. Experimental program

\begin{tabular}{|c|c|c|c|c|}
\hline \multirow{3}{*}{ FRP } & \multicolumn{3}{|c|}{$\mathbf{L}_{\mathrm{ad}}=200 \mathrm{~mm}$} & \multirow{3}{*}{$\begin{array}{c}\mathrm{L}_{\mathrm{ad}}=135 \mathrm{~mm} \\
\text { Masonry stone }\end{array}$} \\
\hline & \multirow{2}{*}{ Block stone } & \multicolumn{2}{|c|}{ Masonry stone } & \\
\hline & & 4 mortar joints & 1 mortar joint & \\
\hline BFRP & $4^{*}$ & $4^{* \S}$ & 2 & $4^{\S}$ \\
\hline CFRP & $3^{*}$ & -- & 2 & -- \\
\hline SFRP & $3^{*}$ & -- & -- & -- \\
\hline FFRP & $3^{*}$ & -- & -- & -- \\
\hline HFRP & $2^{*}$ & -- & -- & -- \\
\hline
\end{tabular}

"Leone el al., 2014

$\S$ Leone et al., 2015

Materials. The utilized substrate is widely found in the South of Italy and called Lecce stone. This calcareous material is characterized by high porosity, easy workability, good aesthetic, satisfactory mechanical and physical properties. The mechanical properties of the stone were experimentally evaluated: compressive strength was determined by compression test on cubes $70 \mathrm{~mm}$ high, according to (UNI EN 1926, 2007); while the flexural strength has been evaluated by three-points bending test on prisms of $30 \mathrm{~mm} \times 60 \mathrm{~mm} \times 180 \mathrm{~mm}$, according to (UNI EN 12372, 2007). As suggested in the standards the possible material anisotropy was considered for the mechanical characterization, therefore the tests were performed on specimens loaded in the direction perpendicular and parallel to the stratification layers of the limestone. The compression tests were conducted on 59 specimens (10 for each directions) at a load speed of $0,1 \mathrm{MPa} / \mathrm{s}$. The kind of failure was in all cases suitable, evidencing the absence of defects and/or inclusions that may cause a premature crisis. As already observed in other works (Aiello and Sciolti, 2006), the effect of the anisotropy on compressive strength resulted almost negligible. Therefore, the compressive strength of the Lecce Stone utilized in the present work can be estimated equal to $21,14 \mathrm{MPa}$ irrespective of the of the loading direction.

The flexural strength of the stone was evaluated by means three point bending tests at a head speed of 0,1 $\mathrm{mm} / \mathrm{min}$. As made for the compression strength determination, it is possible to evaluate the flexural strength of the utilized natural stone by averaging all the experimental results since anisotropy appears irrelevant; the mean value obtained was 4,26 MPa.

Finally, the modulus of elasticity was determined according to (UNI EN 14580, 2005), the value resulted equal to $10850 \mathrm{MPa}$ averaging the test results of 36 specimens.

The mechanical proprieties of the FRP were experimentally evaluated by standard tensile test, ASTM D 3039M (1993). The tests were executed at least on three similar specimens for each type of fibers and the results averaged. The experimental results in terms of tensile strength $\left(f_{u}\right)$, strain at failure $\left(\varepsilon_{u}\right)$, elastic modulus $\left(\mathrm{E}_{\mathrm{f}}\right)$ are given in 
Table 2. In this table, also the axial stiffness of the reinforcement ( $\left.t \cdot E_{f}\right)$, equal to the nominal thickness (dry fibers thickness) multiplied by the elastic modulus, is reported. The mentioned data may be found also in a previous work (Leone et al., 2014; Valluzzi et al. 2012).

Table 2. Mechanical proprieties of FRPs

\begin{tabular}{|l|c|c|c|}
\hline \multicolumn{1}{|c|}{ FRP reinforcement } & $\mathrm{f}_{\mathrm{u}}(\mathrm{MPa})$ & $\varepsilon_{\mathrm{u}}(\%)$ & $\mathrm{t} \cdot \mathrm{E}_{\mathrm{f}}(\mathrm{GPa} \cdot \mathrm{mm})$ \\
\hline CFRP sheet & 2735 & 1,26 & 39,76 \\
\hline SFRP sheet & 2997 & 1,74 & 45,06 \\
\hline BFRP sheet & 1673 & 1,96 & 12,36 \\
\hline HFRP sheet & 447 & 2,32 & 3,01 \\
\hline FFRP sheet & 265 & 1,69 & 3,04 \\
\hline
\end{tabular}

At the date mechanical tests are still in progress on the two types of analyzed masonry substrates and on the utilized resin.

Test set-up. In the Figure 1 the geometrical details of the tested specimens are reported. The specimen is constituted by a composite reinforcement bonded on a prismatic element with nominal dimensions of 250x150x50 mm in the case of single units of Lecce Stone, and 300x120x55 mm in the case of masonry prisms made by Lecce Stone units and hydraulic mortar joints. The bond length is in the range 135-200 $\mathrm{mm}$ while a 40-50 mm length was left un-bonded at the loaded end. The grip system was designed ad hoc by means a steel frame while the tensile force was applied at the specimens through the FRP reinforcement strengthened at its end by a steel plate.
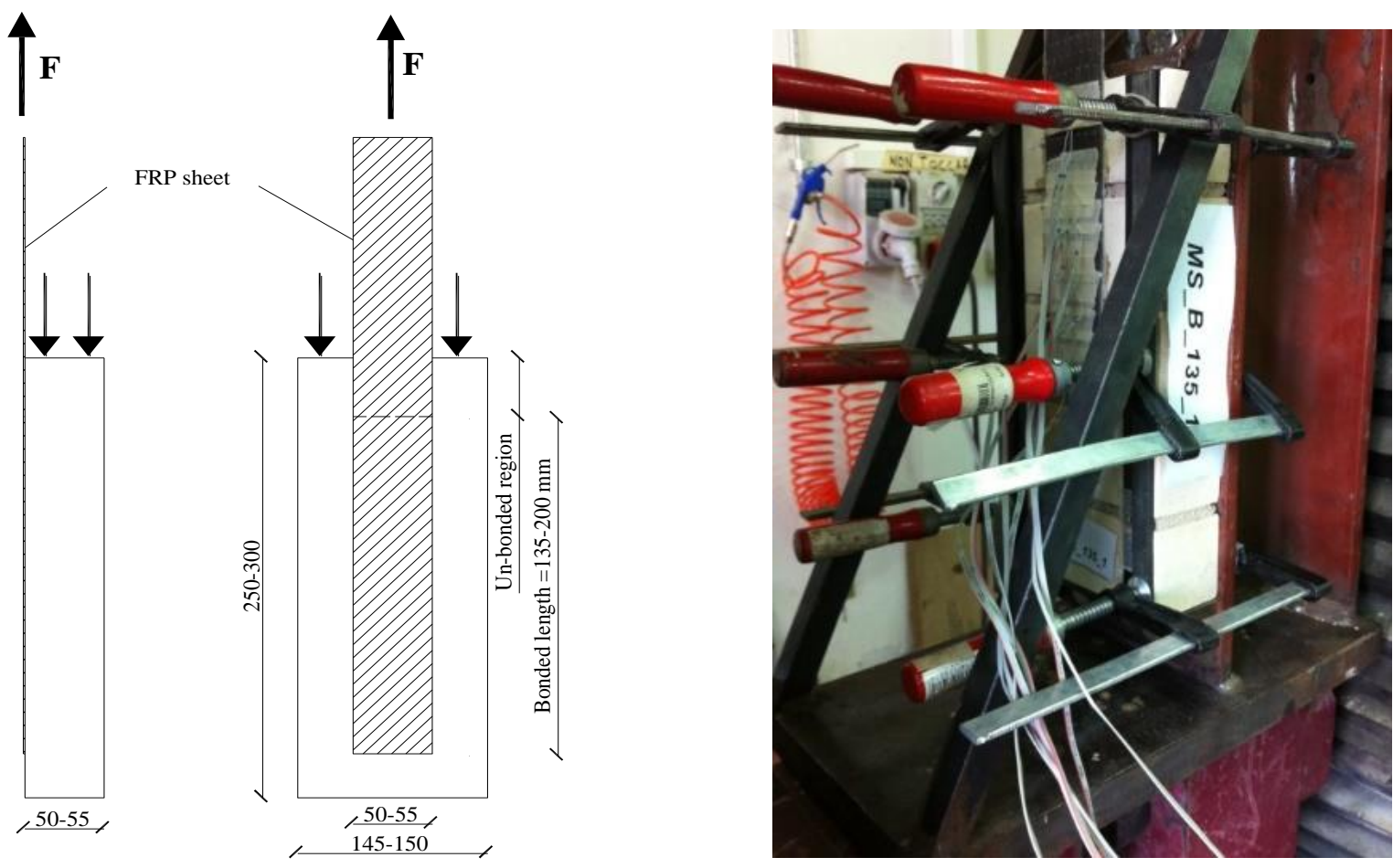

Figure 1. Test set-up 
Electrical strain gauges were applied along the bonded and un-bonded reinforcement to record the strains with increasing the load. All used measuring devices were connected to an electrical data acquisition system directly linked to a personal computer. The tests were conducted at a displacement speed of 0,3 $\mathrm{mm} / \mathrm{min}$.

\section{EXPERIMENTAL RESULTS}

The experimental results were analyzed in terms of bond strength, mode of failure and strains path as detailed in the following.

Bond strength and failure mode. Analysing the results reported in the Table 3 it appears evident as the bond strength increases with the axial stiffness of the reinforcement $\left(t \cdot E_{f}\right)$ while maintaining the same substrate configuration. In fact, similar values of bond strength are obtained in the case of specimens reinforced with CFRP and SFRP sheet (characterized by comparable axial stiffness) when the substrate is realized with units of Lecce stone. For the same reason specimens reinforced by HFRP and FFRP show a comparable bond strength. A similar trend is confirmed referring to the substrate made by stone units and one mortar joint, in fact comparing the bond strength values it results that those obtained when utilizing CFRP are higher than those associated with the use of BFRP.

On the other hand, comparing results related to the different substrate configurations and referring to the same type of reinforcement it is possible to observe as the masonry specimens show a higher value of bond strength for both substrates realized with four and one mortar joints. In fact, an increase of around $33 \%$ was observed comparing BS-B and MS-B specimens while it was around 16\% comparing BS-B and MS2-B samples. A similar trend has been found in a previous work (de Felice et al. 2015) reporting a wide experimental campaign aimed to investigate the bond performance between FRP reinforcements and brick units or bricks joined by mortar joints. The reason of the results may be linked to the different physical and mechanical properties of the stone blocks and the mortar. In fact, during the delamination process the deeper penetration of the epoxy resin within the mortar joints adds a further resistance to the delamination furnishing a positive effect on the global bond strength; this contribution appears more significant than the decay of the mechanical properties of the substrate that should lead to a reduction of the delamination load.

The available data reported in the Table 3 suggests that in the case of masonry substrate a bond length of $135 \mathrm{~mm}$ is not sufficient to guarantee the stress transfer mechanism. In fact, lower value of bond strength were recorded for the specimen MS-B-135 respect to those of the MB-S samples.

However at the date, the available data on the kind of masonry substrate investigated are not sufficient to provide indications with general validity; a wider experimental investigation is needed.

In almost all cases the specimens failed for deboning of the FRP from the substrate with a thin layer of masonry that remains attached to the reinforcement. In some cases the delamination is also accompanied by small cracking of the substrate $(\mathrm{CD}+\mathrm{SC})$, as illustrated in Figure 2a for the specimen MS2-C-2. In the case of masonry substrates the layer of the mortar joints that remains attached to the FRPs is thicker than that of the stone units, Figure 2; this result confirms as above asserted regarding the different penetration of the resin within the mortar and the stone. 

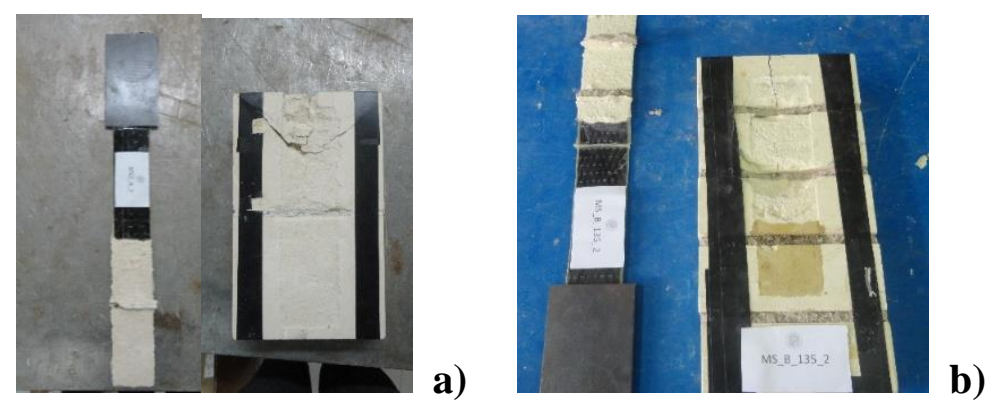

Figure 2. Mode of failure - a) MS2-C-2 specimen, b) MS-B-2-135

In other cases a shear failure of the stone was observed with the delamination of the reinforcement from the substrate $(\mathrm{CD}+\mathrm{WS})$. An example of this kind of failure is reported in the Figure $2 b$.

Table 3. Experimental results

\begin{tabular}{|c|c|c|c|c|}
\hline Specimens & $F_{u}(k N)$ & $F_{\mathbf{u} \_ \text {ave }}(\mathbf{k N})-\mathbf{C O V}$ & $t \cdot E_{\mathrm{f}}(\mathbf{G P a} \cdot \mathbf{m m})$ & Failure mode \\
\hline BS-S-1 & 6,14 & \multirow{3}{*}{$5,48(10 \%)$} & \multirow{3}{*}{45,06} & $\mathrm{CD}$ \\
\hline BS-S-2 & 5,16 & & & $\mathrm{CD}$ \\
\hline BS-S-3 & 5,16 & & & CD \\
\hline BS-C-1 & 6,14 & \multirow{3}{*}{$5,44(11 \%)$} & \multirow{3}{*}{39,76} & $\mathrm{CD}$ \\
\hline BS-C-2 & 5,04 & & & $\mathrm{CD}$ \\
\hline BS-C-3 & 5,16 & & & $\mathrm{CD}$ \\
\hline BS-B-1 & 4,91 & \multirow{4}{*}{$5,22(9 \%)$} & \multirow{4}{*}{12,36} & $\mathrm{CD}+\mathrm{SC}$ \\
\hline BS-B-2 & 5,05 & & & $\mathrm{CD}+\mathrm{SC}$ \\
\hline BS-B-3 & 5,89 & & & $\mathrm{CD}+\mathrm{SC}$ \\
\hline BS-B-4 & 5,03 & & & $\mathrm{CD}+\mathrm{WS}$ \\
\hline BS-F-1 & 2,83 & \multirow{3}{*}{$2,90(3 \%)$} & \multirow{3}{*}{3,01} & FR \\
\hline BS-F-2 & 2,83 & & & $\mathrm{CD}$ \\
\hline BS-F-3 & 2,96 & & & FR \\
\hline BS-H-1 & 2,83 & \multirow{2}{*}{2,90} & \multirow{2}{*}{3,04} & FR \\
\hline BS-H-2 & 2,96 & & & $\mathrm{CD}$ \\
\hline MS-B-1 & 8,09 & \multirow{4}{*}{$6,93(15,43 \%)$} & \multirow{4}{*}{12,36} & $\mathrm{CD}+\mathrm{WS}$ \\
\hline MS-B-2 & 5,52 & & & $\mathrm{CD}+\mathrm{WS}$ \\
\hline MS-B-3 & 6,87 & & & $\mathrm{CD}+\mathrm{WS}$ \\
\hline MS-B-4 & 7,23 & & & $\mathrm{CD}+\mathrm{WS}$ \\
\hline MS-B-1-135 & 5,52 & \multirow{4}{*}{$5,46(24,74 \%)$} & \multirow{4}{*}{12,36} & $\mathrm{CD}+\mathrm{WS}$ \\
\hline MS-B-2-135 & 7,34 & & & $\mathrm{CD}+\mathrm{WS}$ \\
\hline MS-B-3-135 & 4,54 & & & $\mathrm{CD}+\mathrm{WS}$ \\
\hline MS-B-4-135 & 4,42 & & & $\mathrm{CD}+\mathrm{WS}$ \\
\hline MS2-C-1 & 8,09 & \multirow{2}{*}{7,91} & \multirow{2}{*}{39,76} & $\mathrm{CD}+\mathrm{WS}$ \\
\hline MS2-C-2 & 7,72 & & & $\mathrm{CD}+\mathrm{SC}$ \\
\hline MS2-B-1 & 6,50 & \multirow{2}{*}{6,07} & \multirow{2}{*}{12,36} & $\mathrm{CD}+\mathrm{WS}$ \\
\hline MS2-B-2 & 5,64 & & & $\mathrm{CD}+\mathrm{WS}$ \\
\hline
\end{tabular}

$C D+W S=$ Cohesive delamination with removal of wedge stone

$C D+S C=$ Cohesive delamination with small cracks at the substrate

$C D=$ Cohesive delamination

$F R=$ Tensile fibers failure 
Only for the specimens reinforced with natural fiber (HFRP and FFRP) tensile rupture of the FRP reinforcement was observed. In this case the recorded ultimate loads are very close to the ultimate load of the reinforcement, this is due to the poor mechanical properties of the natural fibers in terms of both stiffness and strength.

Experimental strains profile. The influence of the stiffness of the reinforcement on strains profile along the bonded reinforcement can be analyzed in Figure 3Figure 4. The figure 3 refers to the substrate made by Lecce stone units, while figure 4 shows the results obtained for masonry with four mortar joints. The load level is about $50 \%$ and $40 \%$ of the ultimate load in the case of stone units and masonry, respectively. Higher deformations are recorded for the specimens reinforced with a BFRP sheet, while similar strain values are obtained in the case of CFRP and SFRP sheets, Figure 3. Therefore, it is evident as deformations increase with the decrease of the axial stiffness, $t \cdot E_{f}$, as for (BFRP), while similar deformations are obtained for similar $t \cdot E_{\mathrm{f}}$ values (CFRP and SFRP).

In Figure 5 the comparison between the analyzed substrate, in terms of strain versus position curves is reported. For low value of load $(\mathrm{F}=0,5 \mathrm{kN})$, corresponding to $10 \%$ of $\mathrm{F}_{\mathrm{u}}$, the curves seems to be almost similar indicating that, at this stage, the stress transfer mechanism is independent on the type of substrate, Figure 5a. On the contrary, at level of load almost equal to $50 \%$ of the ultimate load the specimens with MS substrate show higher value of deformation along the bond length. This different trend together with the higher recorded value of the ultimate load (

Table 2) underlines the higher energy dissipation capacity of the masonry respect to the stone units; in other words, a higher value of the fracture energy may explain the observed results.

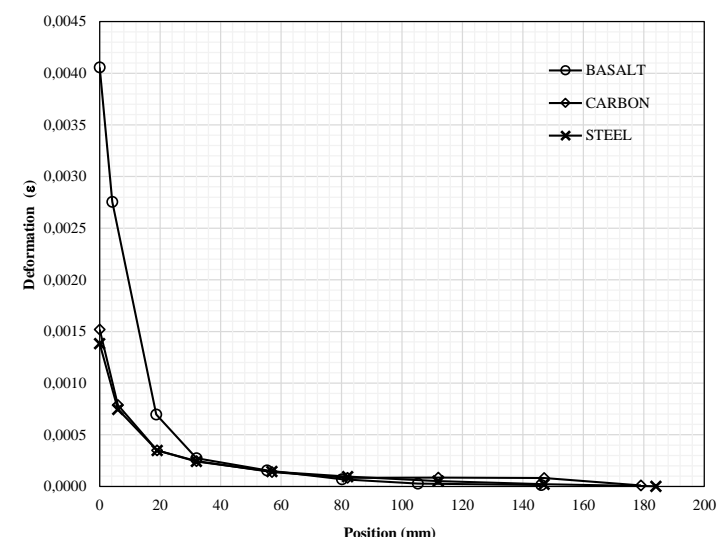

Figure 3. Influence of the stiffness of the reinforcement - units of Lecce stone $-\mathrm{F}=3,00 \mathrm{kN}$

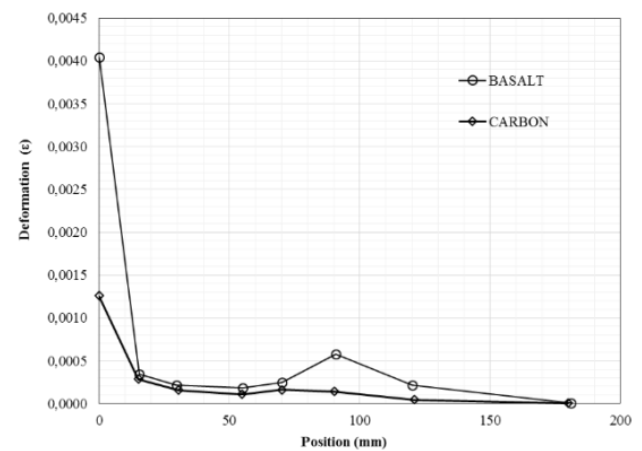

Figure 4. Influence of the stiffness of the reinforcement - Masonry with four mortar joints $-\mathbf{F}=\mathbf{2 , 5 0} \mathrm{kN}$ 

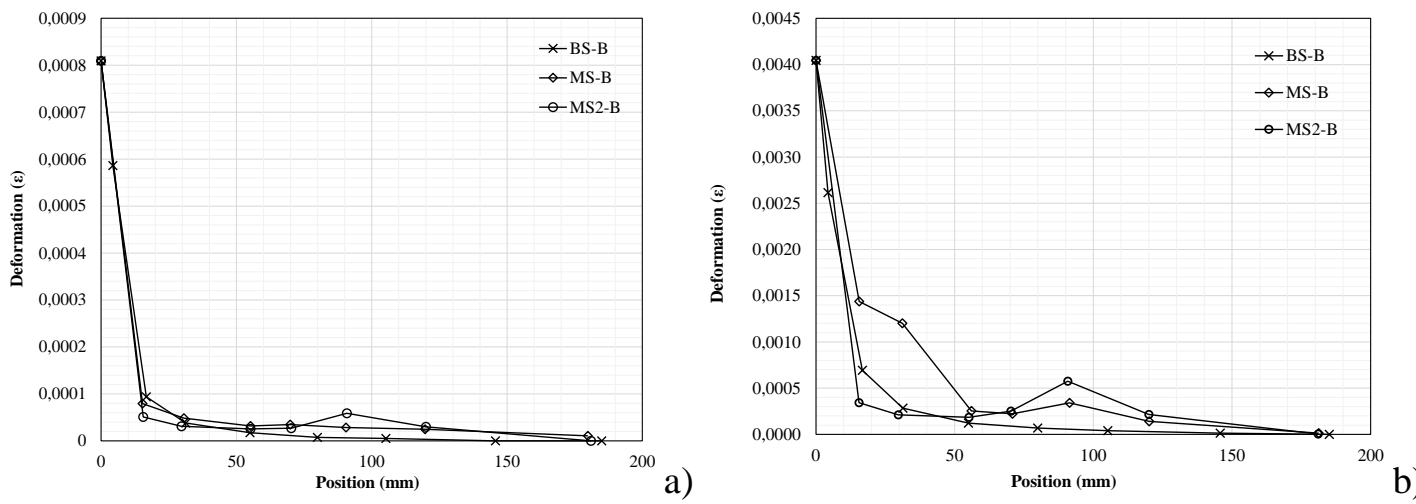

Figure 5. Influence of the type of substrate $-B F R P$ reinforcement: a) $F=0,5 \mathrm{kN}$; b) $F=2,5$ kN

The comparison between similar specimens with different bond length is reported in the Figure 7. In the graph the deformation versus position curves are plotted for two level of load ( $\mathrm{F}=0,5 \mathrm{kN}$ and $\mathrm{F}=2,5 \mathrm{kN})$. On the basis of available data, it is possible to note as the bond length sligthly influence both the deformation trend and values.

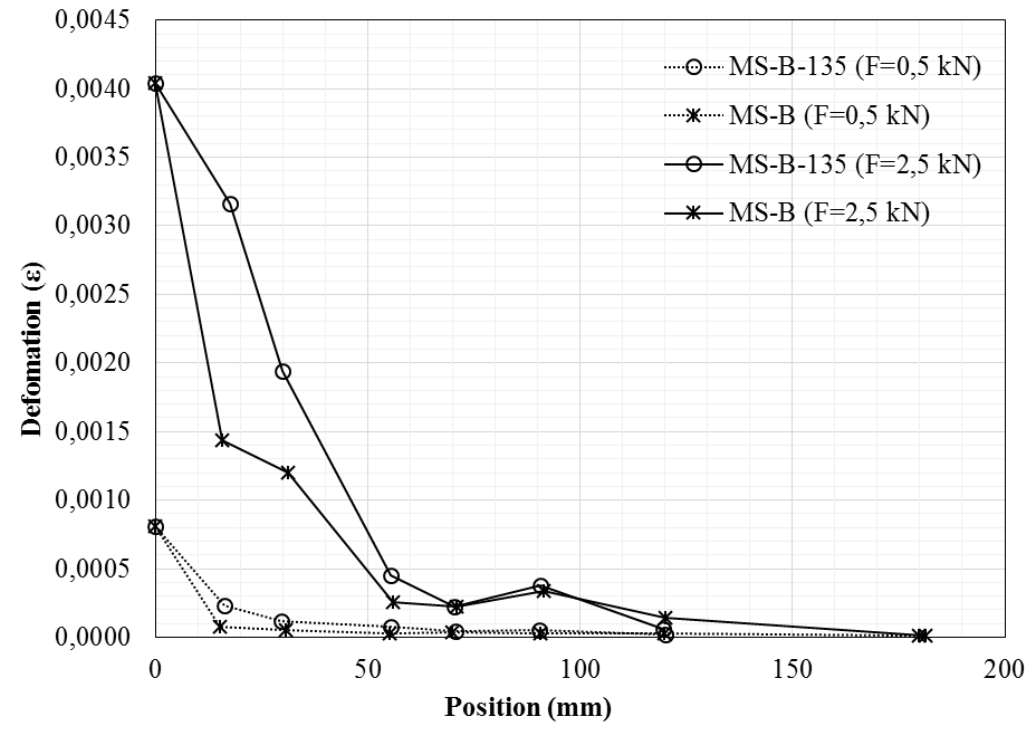

Figure 6. Influence of the bond length

\section{THEORETICAL ANALYSIS}

In order to furnish useful informations from a design point of view, the experimental data were compared with the debonding load predictions provided in literature (CNR DT 200/R1; Ceroni et al. 2014). In particular, the following relationship was used (CNR DT 200/R1):

$F_{\text {max }, t h, m}=b_{f} \sqrt{2 \cdot E_{f} \cdot t_{f} \cdot k_{G, m} \cdot k_{b} \cdot \sqrt{f_{m} \cdot f_{m t}}}$

where $b_{f}$ is the FRP reinforcement width; $E_{f}$ is the modulus of elasticity of the FRP; $t_{f}$ is the FRP reinforcement thickness; $\mathrm{k}_{\mathrm{G}, \mathrm{m}}$ is a parameter to be determined experimentally and according to (CNR DT $200 / \mathrm{R} 1$ ) is set equal to 0,022 in the case of natural stone - limestone; $\mathrm{k}_{\mathrm{b}}$ is given by: 
$k_{b}=\sqrt{\frac{3-b_{f} / b_{m}}{1+b_{f} / b_{m}}}$

Where $b_{m}$ is the substrate width; $f_{m}$ is the compression strength of the substrate; $f_{m t}$ is the tensile strength of the substrate.

Firstly, the experimental database available in [9] was considered since used to set $\mathrm{k}_{\mathrm{G}, \mathrm{m}}$ in (CNR DT 200/R1). Successively the experimental results previous discussed were added to the mentioned database aiming to verify if they follow the trend suggested in the Italian guide line. The estimation of the good fit was done by the R-squared value that, as known, is a statistical measure of how the data well fit the theoretical prediction.

In the Figure 7 the comparisons between experimental points and theoretical predictions is reported According to (CNR DT 200/R1) the theoretical prediction of the ultimate force in the case of masonry substrate was done referring to the mechanical proprieties of the stone unit instead of to those of the masonry.

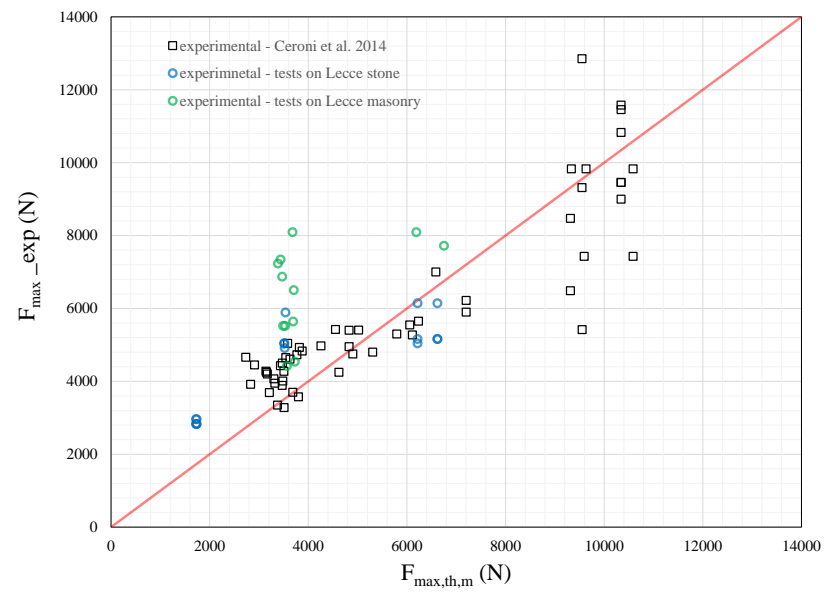

Figure 7. Experimental versus theoretical debonding load

The obtained R-squared values and the percentage difference $(\Delta)$ respect to the R-squared value obtained from database discussed in (Ceroni et al.2014) are reported in the Table 4.

Table 4. R-squared values

\begin{tabular}{|c|c|c|}
\hline Experimental database & $\mathbf{R}^{\mathbf{2}}$ & $\Delta$ \\
\hline Ceroni et al. 2014 & 0,799 & \\
\hline Ceroni et al 2014- + test on block stone & 0,794 & $-0,63 \%$ \\
\hline Ceroni et al 2014- + test on block stone + tests on masonry & 0,686 & $-14,14 \%$ \\
\hline
\end{tabular}

Analyzing the data reported in the table as well as the Figure 7 it is possible to note as adding the experimental data referring to the test on substrate made by stone units the effectiveness of estimation law remains almost the same. In fact, the R-squared value passes from 0,799 to 0,784 with a variation of $0,63 \%$. This observation confirms the validity of the relationship reported in [1]. On the contrary, a slight variation of R-squared value was observed when adding to the database the results related to the masonry; in fact a reduction of the R-squared of around 14\% was obtained. The limited experimental results still available on masonry substrates made by natural stones don't allow to draw relevant conclusions; a wider database is necessary to further check the reliability of extending the relationship provided in (CNR DT 200/R1) to the kind masonry investigated herein. 


\section{CONCLUSION}

In the present paper the bond behavior between different types of both FRP reinforcement and masonry substrate is investigated and discussed. The following general considerations can be drawn:

- The bond strength increases with the stiffness of the reinforcement for the same type of substrate.

- The masonry substrate furnishes a higher value of the bond strength respect to the stone unit. This result may be explained by the bigger penetration depth of the epoxy resin within the mortar joints, that involves an higher resisting contribution to the delamination phenomenon.

- In the case of masonry substrate a bond length higher than $135 \mathrm{~mm}$ seems to be necessary in order to guarantee the whole stress transfer mechanism.

- The theoretical relationship, suggested by the Italian Guideline (CNR DT200/R1), furnishes a good estimation of the experimental ultimate load in the case of specimens realized with stone units. Higher scatters were observed comparing the theoretical prediction with the available data when referring to the masonry substrate. In the last case more researches are still suggested in order to further check the reliability of the available relationships in presence of mortar joints.

\section{ACKNOWLEDGEMENTS}

The work has been carried out with the financial support of the research projects "ReLUIS-DPC 20142018.

\section{REFERENCES}

ASTM D 3039M (1993), "Standard Test Method for Tensile Properties of Polymer Matrix Composite Materials", 1993

Aiello M. A. and Sciolti M. S. (2006) "Bond analysis of masonry structures strengthened with CFRP sheets", ELSEVIER Journal of Construction and Building Materials, 20, pp.90 - 100.

Ceroni F., Ferracuti B., Pecce M., Savoia M. (2014). Assessment of a bond strength model for FRP reinforcement externally bonded over masonry blocks Composites: part B 61 (2014) pp. 147-161

CNR DT 200/R1. Guide for the design and construction of externally bonded FRP systems for strengthening existing structures. Rome (Italy): Advisory Committee on Technical Recommendation for Construction of National Research Council; 2013

de Felice Gianmarco, Aiello Maria Antonietta, Alessandro Bellini, Francesca Ceroni, Stefano De Santis, Enrico Garbin, Marianovella Leone, Gian Piero Lignola, Marialaura Malena, Claudio Mazzotti, Matteo Panizza, Maria Rosa Valluzzi (2015). "Experimental characterization of composite-to-brick masonry shear bond" Materials and Structures, DOI 10.1617/s1 1527-015-0669-4, pp.1-16

Leone Marianovella, Sciolti Margherita Stefania, Micelli Francesco, Aiello Maria Antonietta (2014) "Bond stress-slip behavior of FRP materials bonded to masonry elements" Proceeding of the 9th International masonry Conference - University of Minho - Guimaraes - Portugal- 7-9 July 2014 Editors: Lourenco, Haseltine, Vasconcelos- ISBN: 978-972-8692-85-8 - electronic format

Leone Marianovella, Margherita Stefania Sciolti, Francesco Micelli, Maria Antonietta Aiello, (2015) "The interface behavior between external FRP reinforcement and masonry" Key Engineering Materials Vol. 624 - ISSN 1013-926, pp. 178-185 () (2015) Trans Tech Publications, Switzerland

Sciolti, M.S. , Aiello, M.A., Frigione, M. (2012) "Influence of water on bond behavior between CFRP sheet and natural calcareous stones" Composites Part B: Engineering, Volume 43, Issue 8, Pages 3239- 
3250UNI EN 1926 (2007) "Natural stone test methods - Determination of uniaxial compressive strength"

Sciolti, M.S., Aiello, M.A., Frigione, M. (2015) "Effect of thermo-hygrometric exposure on FRP, natural stone and their adhesive interface", Composites Part B: Engineering, Volume 80, Pages 162-176

UNI EN 12372 (2007) "Natural stone test methods - Determination of flexural strength under concentrated load"

UNI EN 14580 (2005) "Natural stone test methods - Determination of static elastic modulis.

Valluzzi Maria Rosa, Oliveira Daniel V., Angelo Caratelli, Giulio Castori, Marco Corradi, Gianmarco de Felice, Enrico Garbin, David Garcia, Leire Garmendia, Ernesto Grande, Ugo Ianniruberto, Arkadiusz Kwiecień, Marianovella Leone, Gian Piero Lignola, Paulo B. Lourenço, Marialaura Malena, Francesco Micelli, Matteo Panizza, Catherine G. Papanicolaou, Andrea Prota, Elio Sacco, Thanasis C. Triantafillou, Alberto Viskovic, Bogusław Zając, Gina Zuccarino "Round robin test for composite-tobrick shear bond characterization", Materials and Structures, Springer - 2012 45: 1761-1791 